\title{
Microstructure and Surface Morphology of Inconel 625 Alloy Prepared by Laser Melting Deposition using Abrasive-Assisted Jet Electrochemical Machining
}

\author{
Junzhi Liu ${ }^{1}$, Changshui Gao ${ }^{1}$, Lida Shen ${ }^{1 *}$, Haixia Cheng ${ }^{1}$, Xuesong Gao ${ }^{2}$, and Xiao Han ${ }^{3}$ \\ ${ }^{1}$ College of Mechanical and Electrical Engineering, Nanjing University of Aeronautics and \\ Astronautics, Nanjing 210016, People's Republic of China \\ ${ }^{2}$ Nanjing Institution of Advanced Laser Technology, Nanjing 210038, People's Republic of China \\ ${ }^{3}$ Beijing Institute of Space Mechanics and Electricity, Beijing 100094, People's Republic of China \\ *E-mail: 1dshen@nuaa.edu.cn
}

doi: $10.20964 / 2018.11 .25$

Received: 6 July 2018 / Accepted: 19 August 2018 / Published: 1 October 2018

\begin{abstract}
Laser melting deposition (LMD) is typically used for forming and repairing large-scale complex nickel-based superalloy parts, such as aero engines. Defects occur on the surface and structure during LMD and after the completion of forming, so LMD-jet electrochemical machining (JECM) hybrid fabrication was proposed, and a novel abrasive-assisted JECM device was designed. The processing time, and the various processing conditions of the hybrid fabrication were investigated, on account of the balance of processing efficiency and quality. Experiments showed that the oxidation layer of the LMDed samples could be removed entirely under the processing of 90 JECM cycles, while the abrasive-assisted soft brush could efficiently remove the electrolytic products and the abrasive-assisted hard grinding head could efficiently remove the hard-to-electrolyze residual particles in the overlapping areas. The organization microstructure and the surface morphology were characterized using a scanning electron microscope and a 3D optical profiler. The influence that a non-homogeneous distribution of grains (both size and orientation) had on JECM was discussed. The fluctuations of the current efficiencies throughout the processes were analyzed and discussed.
\end{abstract}

Keywords: Laser melting deposition; Electrochemical machining; superalloy; Hybrid fabrication; Microstructure; Surface morphology

\section{FULL TEXT}

(C) 2018 The Authors. Published by ESG (www.electrochemsci.org). This article is an open access article distributed under the terms and conditions of the Creative Commons Attribution license (http://creativecommons.org/licenses/by/4.0/). 